\title{
Artículos
}

\section{Liderazgos colectivos y compartidos: antídoto para una sociedad dependiente de patrones y jefes}

\author{
René Mendoza V. *
}

Recibido: agosto de 2014 / Aceptado: noviembre de 2014

La relación patrón-cliente (patrón-mozo, jefe-subordinado) ha persistido detrás de las grandes obras, sea la construcción de una catedral, mina de oro, la organización de un ejército, la estructura de la Iglesia Católica Romana, o de las haciendas. Con el boom de las organizaciones se habla más de jefes-subordinados, directores-técnicos y presidentes-socios, la que puede llamarse una relación social líder-seguidor. Ese enfoque (el histórico de patrón-cliente y el de líder-seguidor) fue creado en un tiempo en que se dependía de la fuerza física humana y donde la habilidad del líder (patrón o jefe) se creía necesaria. En este artículo se argumenta que el principal obstáculo al desarrollo rural está en la persistencia del 'matrimonio' de ambas relaciones, el de patrón-cliente y el de líder-seguidor, en un contexto en que crecientemente dependemos más del trabajo cognitivo (conocimiento) que del trabajo físico humano. En correspondencia, y en coherencia con la frase de Einstein arriba citada, proponemos un enfoque de liderazgos colectivos y compartidos donde las personas -de las organizaciones, de las comunidades y de las cadenas- liberen sus energías y se hagan líderes visionarios en cada área de la vida, contribuyendo a que cualquier forma de organización social sea más efectiva y llena de vida.

Palyras clave: liderazgo / desarrollo rural / organización social

\footnotetext{
* Colaborador de Wind of Peace Foundation (http://peacewinds.org/research/), investigador asociado de IOBUniversidad de Amberes (Bélgica) y del Instituto Investigación y Desarrollo, Nitlapan-UCA (Nicaragua), y ex director de Nitlapan-UCA.Correo electrónico: rmvidaurre@gmail.com
} 
Leadership is a choice, not a position. Stephen R. Covey (2012, p. xiv)

The significant problems we face cannot be solved at the same level of thinking we were at when we created them.

A. Einstein

\section{Introducción ${ }^{1}$}

"Que se haga lo que el patrón dice," "los gurús nos salvarán," "yo no me mando sola," "estoy esperando que bajen las orientaciones," son frases que expresan la relación patrón-cliente de formas de organización tácitas que construyeron catedrales, haciendas, cooperativas, empresas, universidades, hospitales, ejércitos, insurrecciones contra dictaduras y familias. En algunos casos esa relación social ha sido radicalizada, en particular en organizaciones de seguridad del estado y organizaciones del crimen o mafias. El sentido de lealtad incluso para cometer crímenes o 'ajusticiar' solo ha requerido la orden de una voz detrás del teléfono que reconocen como la del 'jefe' -ver novelas y películas como "En nombre de la rosa," "El padrino" o "La casa de los espíritus". Para el área militar es conocida por ejemplo la influencia de la estructura leninista en partidos y aparatos de inteligencia de guerrillas que llegaron a ser gobiernos, y se dice también que organizaciones secretas buscan inspirarse en la milenaria estructura de la Iglesia Católica Romana, que ha sido capaz de sobrevivir por casi 2000 años. En el caso de Nicaragua, en la guerra de la década de 1980, la Resistencia Nicaragüense reconocía grados a los finqueros que con toda su red social se les sumaban. Todo esto muestra la influencia de las estructuras sociales en las organizaciones de todos los tiempos.

Con el boom de las organizaciones después de la segunda guerra mundial, esa relación patrón-cliente fue obviada, apareciendo la de 'líder-seguidor,' ángulo desde el cual se divide al mundo entre un pequeño grupo de líderes y la gran masa de seguidores (Marquet, 2012). Es un enfoque, incluyendo al de patrón-cliente, creado en un tiempo en que se dependía de la fuerza física humana y donde la habilidad del líder ("saber mandar") -el rey guerrero, el patrón, el inquisidor, el colonizador, el comandante, el pionero, el puntero en la chapia, el hombre cabeza de familia- era necesaria para movilizar (obligar, mandar, ordenar, convencer) a las masas a poner su fuerza física. Ese contexto ha incluido la incrustación de esa relación social en la mente humana, su naturalización y divinización, y en consecuencia el borrar la conciencia tangencial humana: "el líder nace", "siempre necesitamos del patrón," "el mozo no habla delante del patrón," "el patrón es enviado de Dios." Esa estructura vertical es sostenida por toda la sociedad, incluso por quienes enarbolando métodos

1 Este artículo resulta de la experiencia de dirigir el Instituto de Investigación y Desarrollo, Nitlapán-UCA, entre 2012 y 2013, y de trabajar con las cooperativas y jóvenes innovadores desde el año 2010. El tema en cuestión ha sido, sin embargo, de interés personal desde 1988 cuando inicié a hacer inmersiones en las comunidades de El Arenal de Masatepe todos los fines de semana, mientras al mismo tiempo como parte del personal de Nitlapán estudiaba Wiwilí -ver Mendoza (1990). Agradezco a J. Bastiaensen por sus comentarios al borrador de este artículo. 
participativos y relaciones horizontales la antagonizan y rechazan la verticalidad: "el jefe no me dijo, por eso no lo hago". La estructura vive en ellos: "el líder no consulta sus decisiones", critican, mientras añoran un favor o la confianza del líder. La paradoja es que siendo líderes se sienten 'seguidores,' la estructura patrón-cliente habla a través de esa crítica, añoranza y obediencia de cadáver.

El contexto actual, sin embargo, depende más del trabajo cognitivo que de la fuerza física. En Nicaragua, el fin de la frontera agrícola y de la 'vía extensiva' (aumentar producción incluyendo más área), que requirió más del trabajo físico, de sembrar, chapiar y cosechar, está en la siguiente esquina, ya la frontera agrícola llegó al mar, por lo que esa ruta va dejando de ser rentable económicamente ${ }^{2}$. Luego, la economía extractiva (explotación de recursos naturales -forestales, minerales e hidrocarburos- sin mayor industrialización) también va enfrentando problemas, la madera se va agotando, hay cada vez más reclamos en el mundo por el tipo de minería dañina para el medio ambiente, que expresan modelos de enclaves económicos que hasta son contraproducentes económica, social y ambientalmente para el país. Después están los desafíos que implican el cambio climático y la inestabilidad de los mercados para los productos agropecuarios. Todo esto - la urgencia de una agricultura intensiva, la necesidad de aumentar valor agregado a los productos y a los recursos naturales, la variabilidad climática con sus efectos en las enfermedades agrícolas, y la variación de precios que nos presiona a buscar nichos de mercado - nos dice que vivimos en un mundo donde cada actor requiere un mayor conocimiento sobre la complejidad del mundo. Y en el caso de Nicaragua, esto resalta aún más al notar que la oferta de asistencia técnica en el país ha bajado por la reducción de recursos de la cooperación internacional, y que la oferta de crédito rural-agropecuario es mucho menor a raíz de la crisis por el Movimiento No Pago (Bastiaensen, Marchetti, Mendoza \& Pérez, 2013).

En este artículo se argumenta que el principal obstáculo al desarrollo rural está en la persistencia del 'matrimonio' entre el modelo 'líder-seguidor' y la relación patrón-cliente en un contexto en que urge el conocimiento sobre los desafíos mencionados, y sobre maneras de innovación tecnológica y social que permitan a la sociedad usar los mercados como medios en lugar de someterse a ellos. También se argumenta que esas relaciones patrón-cliente y líder-seguidor, independientemente de sus efectos en el desarrollo rural, en sí mismos son degradantes, relaciones de subordinación indeseables que requieren ser transformadas. Reconocemos la dureza de esas estructuras sociales institucionalizadas en la misma mente humana, lo que ha hecho posible que a pesar de los cambios de contexto persistan estructuras centralizadas que limitan la capacidad y potencialidad humana. Tomamos nota de experiencias valiosas que se adelantaron a su tiempo: por ejemplo, el caso de las poblaciones Apaches en Nuevo México en los Estados Unidos que, basados en una modalidad descentralizada de sus liderazgos, resistieron por cinco siglos al ejército español de Cortez, a los mexicanos y al ejército norteamericano (Nevins, 2004); el de los AA (alcohólicos anónimos), fundado por Bill Wilson en 1935, donde no hay

2 En el caso del rubro café, esa vía extensiva facilitó la propagación de la roya, poniendo en evidencia que esa ruta ya no es viable en el norte del país (Mendoza, 2013a). 
jefes; el del campesinado, que persistió a la revolución industrial, al socialismo de la URSS, Cuba, la Nicaragua sandinista de los 80 y a los capitalismos del presente ${ }^{3}$. Y en las últimas dos décadas destaca la estructura descentralizada de Al Qaeda (Brafman y Beckstrom, 2007) y la de Wikipedia, una enciclopedia libre, de rápido acceso al público, que recibe contribuciones escritas y ediciones de forma descentralizada (Jiles, 2005).

Proponemos un nuevo enfoque coherente con el contexto actual de cambio, el de liderazgos colectivos y compartidos, que surge de un cambio de relaciones sociales en las organizaciones y en las comunidades rural-urbanas, donde no hay lugar para seguidores que trabajen 'a medio gas' y que estén 'liberados de pensar'. Dada la dureza de la vieja estructura social, apuntamos elementos básicos para el nuevo enfoque, de un liderazgo que se hace, que cubre todas las áreas de la vida, y que hace más efectiva a cualquier organización y provee sentido de vida único a cada persona.

\section{Marco conceptual}

\subsection{La importancia del trabajo cognitivo}

Covey (2012) afirma que "estamos en medio de los más profundos cambios en la historia de la humanidad, donde el trabajo primario se mueve de la era industrial de 'control' a la era del trabajo del conocimiento 'liberado'" (traducción propia) ${ }^{4}$. Esta afirmación puede parecer inapropiada para los países llamados 'en vías de desarrollo', que no tienen avanzada su industrialización. En el caso de Nicaragua diríamos que se mueve de la era de la agricultura extensiva hacia el trabajo del conocimiento. Aquí describimos esa realidad de agricultura extensiva 'casada' con un modo de organización de las familias rurales, de las cadenas de valor, y de las organizaciones oferentes de servicios, conducidos por la fuerza del mercado, que impiden aprovechar los cambios de contexto, y luego esbozamos el marco que consideramos puede ayudarnos a tomar ventaja de ese contexto de cambio.

En la década de 1940 la frontera agrícola se extendió hacia el norte-interior del país y, desde 1990, hacia las dos regiones de la Costa Caribe (Región Autónoma del Atlántico Norte y Región Autónoma del Atlántico Sur) a tal punto que el 40\% del ganado actual y la extracción de la mayor parte de la madera y la minería, están en ambas regiones. Esta expansión y extracción se ha basado en la ampliación de áreas en condiciones de pobre infraestructura (caminos, carreteras) y en la medida que la

\footnotetext{
3 La población campesina-indigena se reproduce aun en las adversidades. Ellos se parecen a las estrellas de mar, que cuando les cortan uno de los cinco brazos, crean uno nuevo, si le cortas de la mitad más bien se reproduce en dos; no son como la araña que muere cuando aplastas su cabeza (Brafman \& Beckstrom, 2007, p. 41). El campesinado-indigena es descentralizado, y aun cuando le ponen una 'cabeza' (directivo dependiente del Partido, directivo centralista, politicas socialistas de Estado o capitalistas) se escurre.

4 "We are in the middle of one of the most profound shifts in human history, where the primary work of mankind is moving from the Industrial Age of 'control' to the Knowledge Worker Age of 'release"' (Covey 2012, p. xiii). Covey es un estudioso de liderazgos.
} 
extracción de recursos naturales toma fuerza de la mano de grandes -y emergentesempresas, portando una lógica de 'economía minera' que consiste en aprovechar al máximo antes de que cambie el gobierno, se aprueben nuevas leyes o la presión ambientalista se difunda. Por lo tanto, la vía extensiva y la vía extractiva, en lugar de la vía de mayor productividad y agregación de valor industrial, han sido rentables en el país debido a los bajos costos de mano de obra, suelo fértil que no ha requerido de mayores fertilizantes ni insumos químicos, y debido a la abundancia de los recursos naturales.

Esta situación se parece a la de países como Bolivia, Perú y Ecuador, apareciendo Venezuela como un futuro riesgoso que en economía se llama 'la enfermedad holandesa': cuando un país explota recursos naturales que en el corto plazo le significan grandes ingresos y hace que el resto de sectores productivos se vea afectado. Por ejemplo, a cuantiosos ingresos por el petróleo, más apreciación de la moneda local y menos competitividad de la industria nacional. En el caso de Nicaragua formulamos la siguiente hipótesis: la combinación de 'vía extensiva' y 'vía extractiva', debido a que han sido rentables basadas en la abundancia de mano de obra y de recursos naturales, ha hecho que la productividad del país sea baja y que no haya mayor inversión en conocimiento en diferentes sectores de la economía del país.

Este modelo extensivo y extractivo resulta de la relación social patróncliente, un marco que ha coincidido con el modelo 'líder-seguidor' de empresas, organizaciones e instituciones. La relación patrón-cliente tiene como factor distintivo el autoritarismo (o relaciones de patriarcado) que concentra recursos y tiene control sobre la estructura social, lo que sostiene la vía extensiva de las actividades agropecuarias 5 . Esa misma relación se da en lo extractivo, que además se ubica en áreas de frontera agrícola con formas de 'enclave económico' (caso minería) y organización mafiosa (cuando prima la extracción ilegal de la madera). Ligadas a este tipo de organizaciones se hallan diferentes instituciones, incluyendo el Estado y empresas transnacionales, basadas generalmente en relaciones nada transparentes.

5 Contrario a esta descripción podriamos encontrarnos otras sociedades en el mismo país que son más igualitarias, comunidades con al menos el $60 \%$ de familias que han permanecido con sistemas de producción más intensivos y sostenibles, y que generalmente tienen formas de organización más incluyentes y diversas. 
La ilustración $\quad 1^{6}$ contiene frases que subyacen ambos modelos: sabios y ricos están completos; pobre se es por destino y es peor si se carece de explotador; los iletrados no tienen pensamiento y están inhabilitados para innovar; las mujeres no tienen valor; las manos valen en la finca. Esta mentalidad y estructura social generalmente pervive en las familias $y$ en sus organizaciones (cooperativas, asociaciones), y también en las instituciones que les proveen servicios de desarrollo rural y de formación: ONG, donantes, iglesias, universidades, institutos técnicos, institutos de investigación y empresas.
Los sabios están completos.

La innovación es para preparados.

El iletrado no tiene pensamiento.

Los campesinos no tienen títulos, por eso no crean ideas.

$\checkmark \quad$ Los campesinos al machete y al covín, nunca a la cabeza.

$\checkmark \quad$ El que nace para maceta no pasa del corredor.

$\checkmark \quad$ A las mujeres no se les hereda tierra porque no trabajan.

$\checkmark \quad$ Trabajo es en finca.

$\checkmark \quad$ Cabeza de familia es el hombre, lo dijo el Señor.

$\checkmark \quad$ Soy pequeño productor, por eso no tengo voz.

$\checkmark \quad$ Los ricos están completos y los pobres aumentan.

$\checkmark \quad$ El colmo del pobre es no tener quien le explote.

$\checkmark \quad$ Dios hizo pobres y ricos, a mí me hizo pobre.

$\checkmark \quad$ Dios proveerá; y si no provee, es su voluntad.

Ilustración 1. Mitos vestidos de verdades en la población rural

Fuente: Talleres con jóvenes y cooperativistas, 20112013

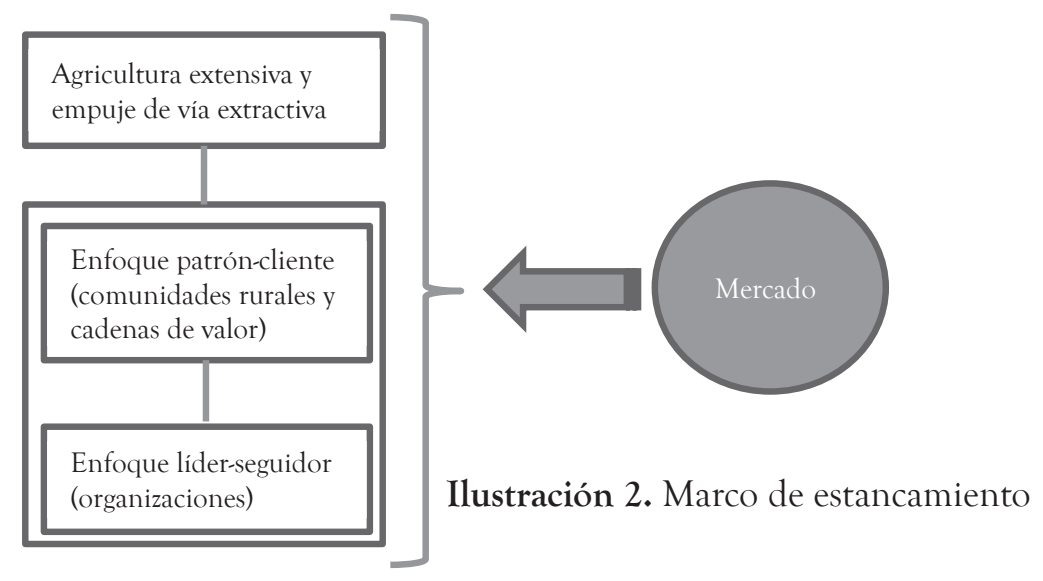

Este 'matrimonio' entre modelos patrón-cliente y líder-seguidor, y entre ambos con la realidad extensiva y extractiva, ha sido rentable, apoyado por la cooperación internacional y demandado por los mercados $^{7}$ (ver Ilustración 2).

6 Las ilustraciones 1 y 2 han sido resultado de talleres organizados con cooperativas, talleres que hemos facilitado conjuntamente con E. Fernández.

7 Por ejemplo, la fuerte demanda de 'comida rápida' de los consumidores de los Estados Unidos hizo que la industria de 'comida rápida' demandara carne barata, lo que fue correspondido por los países de Centroamérica, particularmente Nicaragua, a costa de la deforestación con la expansión ganadera. Ver: Myers (1981). 
Es decir que esa ruta es empujada por la fuerza del mercado que es construido y regulado socialmente por las élites en alianza con gatekeepers locales, generando inequidades (Mendoza, 2012a). Dada esa fuerza, también ha sido capaz de arrastrar agendas como las del 'desarrollo sostenible,' 'equidad de género,' 'reducción de la pobreza,' 'seguridad alimentaria' y 'gobernanza', así como instituciones del 'estado de derecho' y voluntades humanas, todo ello planteado en políticas, proyectos y programas. Sus efectos, expresados en datos de deforestación, concentración de la tierra, desigualdad y pobreza, revelan el problema de ese modelo.

Por los efectos y por los fundamentos de subordinación de ese 'matrimonio', este modelo está hecho para tiempos en que prima la importancia del trabajo físico. El contexto actual es diferente. Primero, se observa un cambio en las condiciones estructurales del país, desde alrededor del 2010 comienza a sentirse el fin de la frontera agrícola: aumento de conflictos con las poblaciones indígenas, reducción de remanentes de bosque, aumento del valor de la tierra junto con decreciente fertilidad del suelo, y crecientes enfermedades para rubros agrícolas (Mendoza, 2013a). Esto significa que no hay otro camino que la productividad y una mejor competitividad en las diferentes cadenas de valor, lo que implica inversión en conocimiento, generando innovaciones tecnológicas, sociales, políticas y económicas. Segundo, bajo el gobierno de Ortega hay mejoría en la infraestructura, expresada en reparación y apertura de caminos rurales, al igual que establecimiento de agroindustrias como mataderos, centros de acopio de leche y procesadoras de maíz, ubicados cada vez más en el interior del país. Estas inversiones aumentan el valor de la tierra, dinamizan el comercio y acrecientan el flujo de información, lo que constituye oportunidades para intensificar las actividades agropecuarias y no agropecuarias. Tercero, hay un capital humano y social creciente. El número de hijos de productores con estudios superiores crece a tal punto que hoy en día casi no hay comunidad rural que no cuente con jóvenes técnicos que pueden contribuir en la mejoría de sus fincas familiares. Y el país tiene miles de cooperativas -mientras en la década de 1970 no pasaban de los dos dígitos- que además han escalado en formas de organización de segundo y tercer grado, incluyendo su decisiva influencia en productos (y cadenas) como el café vía comercio justo, productos lácteos y cacao (Mendoza 2012b). Cuarto, el 'efecto cascada' de la concentración y acumulación de la tierra junto con modalidades de plantaciones avanza en el país, sea en torno a árboles maderables como energéticos: palma africana, bambú, maní, caña de azúcar, cacao, turismo rural, café o ganadería. ${ }^{8}$ Este sistema despoja a las familias campesinas de sus tierras, no absorbe ese empleo 'liberado' ni estudiado, más bien las expulsa ${ }^{9}$ del país, y coopta y subordina a las organizaciones campesinas a una racionalidad económica funcional para la élite. Esto significa que las élites del viejo modelo, ahora transnacionalizadas, van apropiándose de los recursos naturales y de las oportunidades de las inversiones públicas y de la creciente demanda mundial de

8 Para un recuento de datos sobre tenencia de la tierra hasta 2010, ver: Baumeister (2010).

9 El flujo de emigración ha aumentado, destacándose la emigración temporal en periodos de cortes de café hacia El Salvador, Honduras y Costa Rica porque en dichos países les pagan mejor en los cortes de café (Baumeister y Fernández, 2007) 
productos agropecuarios y forestales..$^{10} \mathrm{~A}$ la vez van bloqueando la posibilidad de que el viejo modelo se transforme y la ruta de intensificación se viabilice. Finalmente, hay creciente número de cadenas de valor para los diferentes rubros, que llegan a diferentes mercados. Sin embargo, la mayoría de las familias productoras, aun agregando valor a sus productos, no logran aprovechar las ventajas que el participar en esas cadenas implica en buena medida debido a que dichas cadenas requieren mayor conocimiento expresado en productos con mejor calidad, y cumplimiento con los tiempos y en las cantidades acordadas.

¿Por qué generar cambio del matrimonio nefasto de la Ilustración 2? Por las cinco razones que a continuación se resumen de nuevo: 1) fin de la frontera agrícola, abriendo la puerta a la productividad y competitividad que requieren de conocimiento (trabajo cognitivo); 2) mejoría en inversiones de infraestructura; 3) emergencia de mayor capital humano y organizaciones campesinas que pueden asumir ese reto del conocimiento; 4) el punto anterior no aprovechado debido al bloqueo de parte de las élites; y 5) por la existencia de cadenas de valor que con el viejo matrimonio de la Ilustración 2 no provee beneficios a las familias de pequeños productores.

El nuevo contexto, que reclama con urgencia una agricultura intensiva sostenible ambiental y socialmente requiere, pues, de otra forma de organización social. Las señales que observamos indican que el viejo modelo se va adaptando a los tiempos sin mover un ápice en el modelo de relaciones sociales 'casadas.' Por ejemplo, las plantaciones (de cacao, palma y forestales) que van emergiendo son de 'tipo hacienda' con la diferencia de que usan tecnología intensiva y mecanizada, igual que la extracción minera "a cielo abierto." Hay familias campesinas con hijos estudiados que se tensionan en lugar de cooperar -el hijo que llega como el 'sabio' a cambiar la finca y el padre que le responde que él 'manda' en la finca hasta que muera- porque se enfrentan dos mentalidades: 'el chancho suelta la manteca hasta que muere' versus 'el iletrado no tiene pensamiento'. Las cooperativas responden a las organizaciones del comercio justo con formalidades -llenando actas para hacer constar que su consejo de administración se reúne cada mes, igual que las ONG reportando lo que los donantes quieren escuchar sin que su personal lea ni escriba tratando de entender el nuevo contexto. Esas relaciones sociales más bien se han trans-nacionalizado; muchas veces 'el patrón' está en el exterior -sea agencias de cooperación, mercados, instituciones académicas, estados transnacionales. Las nuevas condiciones materiales descritas, a diferencia de la vieja teoría marxista, no parecen determinar nuevas formas de organización ni nuevas mentalidades. ¿Qué modelo de liderazgo requiere ese nuevo contexto y cómo se genera?

10 El crecimiento de la población mundial (en el año 0 éramos 300 millones de habitantes, en 1900 éramos 1.7 mil millones, en 2000 fuimos 5.7 y en el 2100 seremos 11.2) y el aumento en los ingresos de poblaciones de los países BRICS (Brasil, Rusia, India, China y Sudáfrica) constituyen demandas sostenidas y crecientes de alimentos, lo que para Nicaragua significa mayor demanda de carne y leche (ganadería), café, granos básicos... y demanda de productos cada vez más diferenciados. 


\subsection{Enfoques}

El primer enfoque, y el más dominante, es el neoliberal. Éste, con la noción de 'gobernanza global', concibe que a través de la de-regulación del Estado, la privatización y formas de organización descentralizada (empresas y ONG), se transforman las formas de dominación tradicional y se logra la libertad individual. La meta del neoliberalismo es, a través de diferentes organizaciones, reducir al mínimo al Estado; el control ya no viene del Estado sino de las empresas y la organización es reducida al sector privado. Con esta visión, el neoliberalismo se concibe incompatible con la democracia porque ésta es la puerta para que las masas tomen ventajas del bien común (Boudon, 1981). Viendo que esas masas distorsionan el sistema, las elites reaccionan con lo que Marx llamó 'acumulación originaria'. Es decir, si las masas tienen control desde abajo, se asume que harán mal uso del bien común (p.ej. el mercado), por lo que es necesario que una minoría controle a las masas o privatice, las subordine a los mercados.

La fuente más inspiradora del neoliberalismo es F.A. Hayek, quien propuso el sistema libre de precio para compartir y sincronizar conocimiento personal y local, lo que -según él- permitiría a los miembros de la sociedad activar fines diversos y complicados a través de principios de "auto-organización espontánea" (Hayek, 1944). Hayek (1988) argumentó que había que dejar al mercado hacer todo, que la función del estado era proteger al mercado, que el sistema libre de precios era, como el lenguaje, resultado de la acción humana pero no diseñado por los humanos. La contradicción en Hayek es que la sociedad no puede ser planificada por los humanos pero el mercado guía y hace todo. "Auto-organización" aparece equivalente a "orden espontaneo" y éste es diferente de organizaciones, éste se trata de redes libres, no creadas, controladas ni controlables por nadie, mientras que las organizaciones son redes jerárquicas, creadas y controladas por humanos. No es preocupación de Hayek que el Estado sea democrático o no, porque él prefiere "dictaduras liberales a gobiernos democráticos carentes de liberalismo" (Farrant, Mcpahil \& Berger, 2012, p. 513) -se refería a la dictadura de Pinochet en Chile.

El segundo enfoque es el de la organización jerárquica, patrón-cliente y líderseguidor, que ya hemos referido en páginas previas. Esta perspectiva nos hace dividir el mundo entre líderes y seguidores, es la de controlar personas, es la estructura que entra en nuestra mente desde que leemos en el colegio La Ilíada, Beowulf y La Odisea, y permea en películas como Master and Commander, donde los líderes son héroes individuales. Con esta estructura se crearon pirámides, imperios y fábricas de la revolución industrial, se ha creado riqueza, y por eso es difícil que se rinda. Fue creado en un tiempo en que se dependía de la fuerza física para optimizar la extracción del trabajo físico humano, mientras en la actualidad el trabajo más importante es cognitivo, por lo que esa estructura ya no es óptima. El problema con este enfoque es que las personas tratadas como seguidores actúan como tales y tienen expectativas de seguidores, con limitadas decisiones y desmotivadas a dar su energía, pasión e intelectualidad. Bajo esta óptica, el éxito de una empresa está siempre ligado a la habilidad del líder.

El tercer enfoque, y es el que proponemos como una perspectiva que puede revolucionar la vida de las personas y sus organizaciones, es el de líder-líder. Marquet 
Encuentro №. 99, 7-29, 2014

(2012) lo experimentó en un submarino nuclear, y lo traigo a colación porque un submarino nuclear es un ambiente de lo más cerrado y bajo reglas militares estrictas. Si aun en ese tipo de organización se pudo cambiar, ¿no es acaso posible generar cambios en organizaciones menos cerradas y menos estrictas que un submarino nuclear? Este enfoque 'líder-líder' es donde todos pueden ser líderes y usar sus habilidades de liderazgo en cada aspecto de la vida. Liderazgo no es una cualidad mística de unos, no se nace líder, se hace. Marquet habla de tres elementos para este enfoque: el tener control caminando en dos pies (tomar decisiones e inter-acción para resolver problemas en cada área de la organización, obviando los procedimientos verticales), el de competencias (saber específico, pensamiento deliberado ante las acciones, y aprender en vez de ser capacitado), y el de claridad (conocer el propósito de la organización y los criterios para tomar decisiones).

Al virar hacia la realidad del país este enfoque 'líder-líder' requiere ser adaptado a través de cuatro elementos. Primero, mientras Marquet pudo explicitar lo subyacente en el enfoque 'líder-seguidor', incrustado en la organización militar y encerrado en un submarino, en el caso nuestro las creencias y mitos derivados de la relación social patrón-cliente (p.ej. mitos de la Ilustración 1) y líder-seguidor se reproducen en y fuera de las organizaciones. Segundo, los mecanismos de control, competencias y claridad pudieron ser trabajados precisamente porque se hallaban encerrados en un sub-marino por prolongados períodos de tiempo. En cambio, en una cooperativa sus asociados y líderes se ven esporádicamente, y en una ONG o institución del Estado los funcionarios pasan más tiempo fuera de sus organizaciones, por lo que sus creencias y racionalidades que se alimenta en la sociedad se imponen en sus organizaciones. Tercero, todo el personal del submarino tenía alta escolaridad y formación, mientras aquí trabajamos con familias de baja escolaridad y con saber proveniente de sus experiencias transmitida a través de sus familias y, más que por el saber, las familias están mediadas por instituciones como el 'patriarcado ${ }^{11}$.' Cuarto, al interior del submarino lo político - entendido como 'conciencia de la contingencia humana' por ejemplo, de que pueden dirigir el submarino- había sido adormecido debido a un tipo de liderazgo vertical absorbido por los procedimientos militares internos (reglamentos). Ese adormecimiento se hallaba en la expresión "hago lo que me han dicho que haga”. Sin embargo, en cuestión de días todo el personal inició a cambiar y ser partícipe en la dirección real del submarino. No
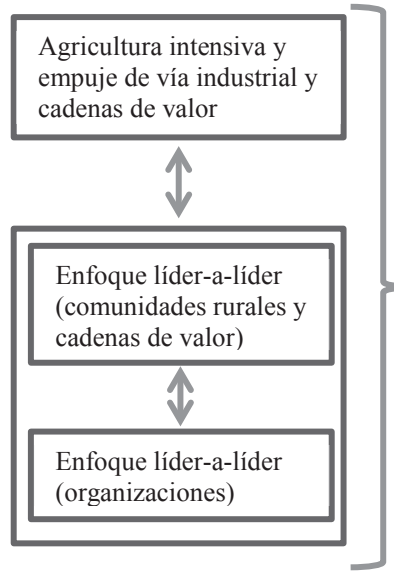

Ilustración 3. Marco

de liderazgo colectivo y compartido

11 E. Fernández (2013) ha estudiado el patriarcado desde la época precolombina hasta nuestros días. Él revela cómo esa institución ha permeado sistemas políticos, religiosos y económicos, y cómo hoy en día moldea la organización de las cooperativas. 
obstante, el adormecimiento (alienación) en nuestras sociedades es un acumulado de siglos, como puede apreciarse en la Ilustración 3, y prevalece la idea naturalizada de que la fuente de los cambios sociales es Dios y no los humanos. ${ }^{12}$

Aunque estos cuatro puntos expresan la especificidad del contexto de países en desarrollo, como es el caso de Nicaragua, también tomamos nota de que ese cambio de 'cultura organizacional' no solo se ha dado al interior de un submarino, también empresas de diverso tipo, hospitales y centros de educación han aplicado de forma creativa los fundamentos del 'manejo de libro abierto.' Este enfoque es el 'gran juego de los negocios' que nace en las empresas y tiene el potencial de cambiar a cualquier organización y a la misma vida de las personas. Esta perspectiva (Stack, 1992) se compone de tres elementos: 1) conocer y enseñar las reglas de una organización a toda su membresía o personal-staff, porque para jugar el juego de la organización todos requieren conocer las reglas y porque solo juntos pueden ganar; 2) mantener un buen puntaje en los resultados de una organización sea en términos de cantidad de producción, calidad del producto, ingresos totales, ganancias, aportaciones, o en el buen impacto que las acciones de una organización provocan, y lograr que cada miembro de la organización de seguimiento a las actividades que permiten lograr dichos resultados; 3) tener voz y agencia en la organización, lo que se logra con el compromiso de cada miembro de la organización por que se hagan las cosas para lograr éxito en la organización, es sentido de apropiación y que al lograr éxitos los beneficios lleguen a todas y todos.

El enfoque 'líder-líder', con sus mecanismos de control, competencias y claridad, al trabajarse incluyendo los cuatro elementos societales (des-aprender, interacción, fuentes de aprendizaje, contingencia), se amplía a un enfoque de liderazgo 'colectivo y compartido,' de interacción humana y de articulación entre familias de las comunidades y cadenas que van transformando su relación social patrón-cliente, y organizaciones que también van transformando su relación social líder-seguidor, ambos en la medida que responden al momentum del nuevo contexto de cambio del país de la vía extensiva a otras formas de organización societal interactuando con diferentes mercados (ver Ilustración 3). De aquí nuestra hipótesis es que este nuevo contexto de cambio que el país vive con la misma estructura de relación patróncliente y líder-seguidor seguirá produciendo más pobreza, despojo y exclusión social, mientras el nuevo enfoque de liderazgos colectivos y compartidos respondiendo a la coyuntura actual de un contexto de cambio, podría contribuir decisivamente a la transformación del país. Con este ángulo, las siguientes dos secciones son trabajadas con los tres elementos propuestos por Marquet -control, competencias y claridadprecediendo la identificación de mitos como ideologías subyacentes en interacción entre la sociedad y sus organizaciones vinculadas al nuevo contexto. 


\section{En las organizaciones cooperativas}

Para 2011 en Centroamérica había 8,282 cooperativas, de las cuales 3,410, o sea el 41\%, está en Nicaragua (datos de INFOCOOP, 2012; ver Mendoza, 2012b). De ese total de 3,410 cooperativas, 821 son cooperativas agropecuarias, número que puede aumentar si discernimos que muchas cooperativas "agroindustriales", "ahorro y crédito", "multifuncional", "multisectorial" y "multiservicios" son también agropecuarias. Además de las cooperativas de primer grado, crecen las cooperativas de segundo y tercer grado. En correspondencia, las cooperativas han ido incluyendo la producción, procesamiento y exportación, así como servicios de crédito y de asistencia técnica. La paradoja es que en la medida en que el cooperativismo ha escalado organizacionalmente, de primero a segundo y a tercer grado, cada nuevo grado ha absorbido las funciones del grado anterior, ha concentrado los recursos y centralizado los servicios, volviéndose "enano cabezón": altas inversiones en la cabeza (cooperativas de segundo grado) con pies de barro (cooperativas de primer grado) (Mendoza, Gutiérrez, Preza \& Fernández, 2012). Y en la medida en que las cooperativas escalan en la cadena de valor, asumiendo por ejemplo procesamiento y comercialización de productos, más tienden a empobrecer a sus asociados (CIPRES, 2008). Por su lado, las familias campesinas-productoras, ante dichos mecanismos de controlarlos y quitarles autonomía, se escurren, diversifican sus mercados y fortalecen sus estrategias familiares, pero pierden el medio (instrumento) que ha sido su organización para escalar económicamente y mejorar en sus niveles de vida como familia (ver nota al pie No. 5). ¿Cómo es posible esa paradoja de 'empeorar mejorando'?13 La fuerza del mercado absorbe al cooperativismo. Al escalar a la agroindustria y a servicios de comercio (exportación) el aparato se privatiza, sustituye a la organización y se vuelve empresa. Las cooperativas se convierten en cooperativas privadas y al hacerlo la riqueza se concentra, el gerente sustituye a la sociedad

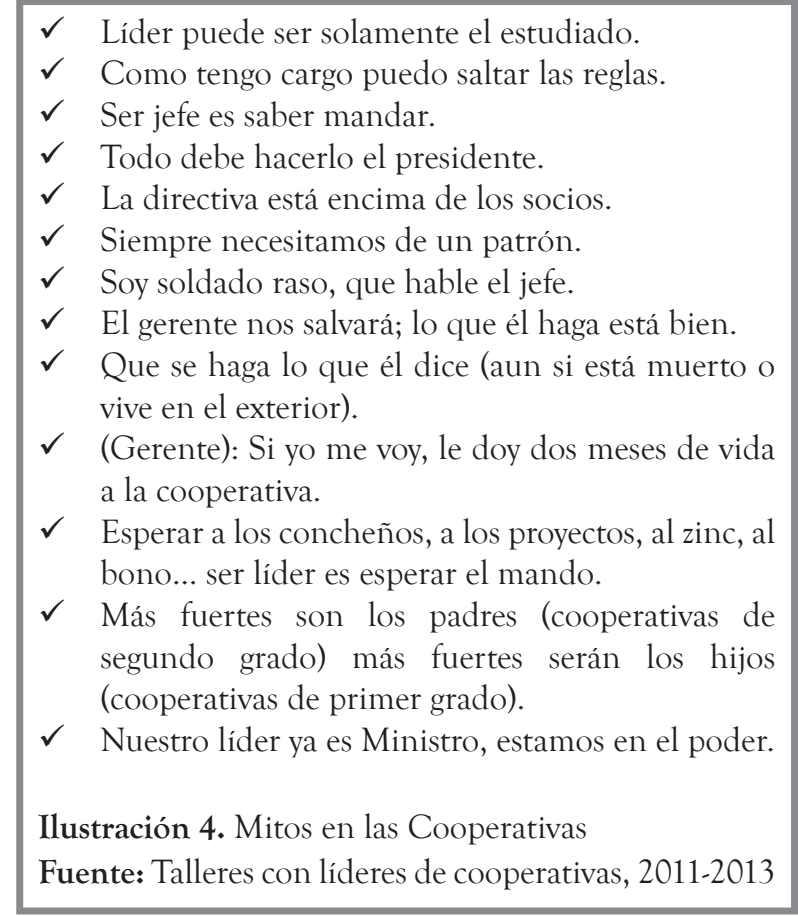


y los asociados se empobrecen (comunicación personal, O. Núñez, 26 de septiembre de 2013). Ese 'mercado' está enraizado en las estructuras sociales y de poder. Siglos de relación patrón-cliente han sido interiorizados por las familias campesinas y las estructuras de intermediación, incluyendo a los líderes y profesionales. Los mitos presentados en la Ilustración 4 son asumidos como verdades que guían y gobiernan las acciones humanas. ¿Cómo puede un socio -y líderes- cambiar su creencia de que es 'soldado raso,' de que los líderes son 'héroes', 'padres', 'dioses', 'estudiados,' 'imprescindibles' y con derecho a obviar las reglas de su organización? ¿Cómo puede un socio superar su alma de mozo y convertirse en líder? ¿Cómo una lideresa puede descubrirse como tal en lugar de verse como 'seguidora' y 'esperar'?

El reto no es solo aprender ciertas técnicas, es aprender para cambiar, lo que es posible si ese aprendizaje se combina con un 'despertar': ciertas verdades son como 'demonios' que nos mantienen hechizados, pero al darnos cuenta del hechizo -en el lenguaje religioso, al 'exorcizarnos' - esas verdades aparecen como mitos, y en ese momento descubrimos nuestras capacidades y la potencialidad de nuestras habilidades. Este paso en raras ocasiones es suficiente para 'no parar de andar jamás' ${ }^{14}$; en la mayoría de los casos es insuficiente. ¿Cómo pueden las cooperativas contribuir a ese 'despertar' y sostener la transformación de sus asociados, en lugar de contribuir al hechizo y a empobrecerlos?

Las cooperativas son formas de organización inventadas por los humanos, y por lo tanto cambiables y mejorables. En coherencia con esta conciencia contingente, para garantizar que las cooperativas sean un medio en función de las familias asociadas, es fundamental que sus asociados sean partícipes de las decisiones

$\checkmark$ Control: aportar capital y ser parte de las decisiones de la cooperativa

$\checkmark$ Competencia: ser parte del liderazgo rotativo a través de los órganos de la cooperativa, y desarrollar intercambio de saberes y de pensamiento entre diferentes organizaciones

$\checkmark$ Claridad: tener un sistema de información abierta para todos los asociados

Ilustración 5. Mecanismos de transformación sobre el funcionamiento y rumbo de su organización. ¿Cómo ser parte de las decisiones? Ver la Ilustración 5. Primero, dice la Biblia "donde está tu tesoro ahí está tu corazón": cada socio debe tener aportaciones en su organización para que ésta tenga patrimonio del cual proveer crédito a sus mismos asociados con bajas tasas de interés. Un socio con aportaciones en su organización será más exigente con sus directivos pues sus recursos (“tesoro”) estarán en juego ${ }^{15}$. Una cooperativa de base con patrimonio propio tendrá más autonomía, más amistades (vínculos) y evitará

14 Kate Choping escribió una novela titulada The Awakening en 1899 en los Estados Unidos. Esa novela fue tan duramente criticada en aquella época que la autora nunca más volvió a escribir. Un siglo después la novela fue reconocida y considerada como 'novela clásica.' La novela trata de cómo una mujer, llamada Edna Pontellier, despierta de su rol de esposa y madre, de garantizar que las empleadas hagan su trabajo, y de que su matrimonio por conveniencia y no por amor aparentase funcionar ante la sociedad de entonces. Ella despierta cuando aprende a nadar en el mar, en ese acto se da cuenta de que puede lograr lo que se propone, eso le hace sentir extraña a la par que va descubriendo que la vida que lleva no es la que ella quiere. Entonces Edna recupera su pasión por la pintura, vende sus cuadros y genera sus ingresos, sale de su casa, pasea y se enamora, estrellándose contra las normas de la sociedad de entonces que -obviamente-la condena. Agradezco a J. Estrada por introducirme a esta novela y por este resumen.

15 Un principio de la cooperativa es "un socio, un voto". Sin variar este principio formal, aqui estamos proponiendo que un socio con aportaciones ("tesoro") tendrá aún más interés en tener "voz" y "voto". 
que su organización de segundo grado se vuelva concentradora y centralizadora. En este sentido, su regla, a diferencia de lo indicado en la Ilustración 4, será: "más fuertes son los hijos más fuertes son sus padres". Y por el rol beligerante de cada asociado (y la presión de su propia familia), debido a que tiene también interés en cuidar "su tesoro" (aportaciones), estará ejerciendo rol de liderazgo aun sin ostentar cargo alguno.

Segundo, la ley de cooperativas y en correspondencia los estatutos de cada cooperativa muestran un camino que, de seguirse, harían exitosa a cualquier cooperativa y por lo tanto tendrían en cada asociado un líder - mujer u hombre. El mayor problema de las cooperativas del país es que obvian ese camino debido al peso de reglas del juego donde la correlación de fuerzas es fuertemente influida por las reglas de la familia, del Partido y del mercado, y en consecuencia las cooperativas caen constantemente en crisis, incurriendo en problemas administrativos, cooperativas privatizadas por sus gerentes o controladas por empresas, con asociados quejosos e impotentes a quienes solo les queda protestar. El desafío mayor es generar cambios en la correlación de fuerzas que incluyen reglas formales e informales que les puedan dar mayor voz a los miembros de las cooperativas.

Algunos buenos líderes de cooperativas de base son presionados y descalificados, y de forma grotesca cuando esos líderes son mujeres, por gerentes y directivos de cooperativas de segundo grado. Esos buenos líderes necesitan que el consejo de administración funcione y que se multipliquen las asambleas generales para discutir y tomar acuerdos-decisiones, y así respaldarse y evitar ser domados o ser obligados a renunciar. Los presidentes -y miembros directivos- que reciben estipendios buscan re-elegirse indefinidamente, y para ello -usando reglas informales del patriarcadoendeudan a algunos líderes que se resisten a dar su voto o buscan beneficiarlos con proyectos, hechos que afectan el crecimiento de liderazgos en la cooperativa, pero que podrían ser remediados si la junta de vigilancia, por ejemplo, asumiese sus funciones que incluyen el hacer cumplir los estatutos y la ley de cooperativas que indican que los directivos solo pueden re-elegirse por una sola vez. Los gerentes suelen sustituir a los directivos, tener poder generalísimo, y en las asambleas inciden más que cualquier miembro directivo, cuando los estatutos indican que en las asambleas solo participan los asociados y no los empleados, y que las decisiones estratégicas les corresponden a los directivos mientras lo operativo, de ejecutar dichas decisiones, le corresponde a la gerencia y al resto del personal técnico-administrativo. Buena parte de las cooperativas tienen comité de crédito, al que generalmente obvian. El presidente o el gerente termina tomando decisiones de a quién, cuánto y cuándo dar crédito, y por eso los directivos y su clientela resultan generalmente endeudados con los montos más altos -creen que ser directivo y ser gerente (regla informal) es 'pasar por alto' las reglas (formales) de la cooperativa. En muchas cooperativas las actas son escritas por los mismos gerentes y no por el secretario de actas, incluso en algunas cooperativas se escriben actas sin que haya reunión del consejo de administración, actas que luego los técnicos llevan a la casa de cada miembro directivo para que sean firmadas. Son actas con contenidos manipulados, cuando los estatutos indican que es la persona nombrada por la asamblea quien tiene que escribir las actas y guardarlas debidamente dado que éstas son la memoria histórica del conocimiento acumulado de una organización. De lo anterior, los mismos estatutos indican el 
camino para convertir a una cooperativa en escuela de liderazgo y contienen las normas apropiadas para que una organización sea exitosa. Lo que se requiere es cambios en las correlaciones de fuerzas que permitan usar de mejor manera las reglas y principios del cooperativismo.

Si cada asociado tiene sus aportaciones ("tesoro”) buscará que su organización siga el camino indicado por sus estatutos, y en la medida que la cooperativa sigue ese camino (aportación + cumplimiento de reglas) estimula a cada asociado a redoblar sus esfuerzos por aportar más capital y por tener mayor participación en los diferentes órganos de su organización ${ }^{16}$-o en lugar de comenzar con aportaciones tener reglas para intensificar la agricultura y organizarse efectivamente para llevarla a cabo ${ }^{17}$. Ese interés efectivo puede ser alimentado a través de intercambio de pensamientos entre las organizaciones. Cada cooperativa de forma deliberada organiza visitas a otras organizaciones; de forma deliberada significa que identifica sus dudas y dificultades para aprender de cómo otras organizaciones han respondido esas dudas y resuelto tales dificultades y, a la vez, contribuir a su auto-estima compartiendo sus logros, que pueden ser de utilidad para otras organizaciones. Mirarse en el 'espejo ajeno' hace redescubrir los propios 'lunares' y lo valioso de las propias 'huellas'.

Tercero, cada asociado necesita tener claridad de que la cooperativa es un medio cuyo propósito es proveerle servicio y ser escuela de formación de liderazgos para viabilizar la ruta campesina-finquera en el caso de las cooperativas rurales. Contando con los dos puntos antes mencionados, la cooperativa necesita ser transparente con los dueños de la organización. Transparencia significa que la información de cada servicio llegue a sus asociados, estén en papelógrafos pegados en las paredes de las oficinas de la cooperativa y/o se impriman para ser entregados a cada socio de forma permanente. ¿Qué información? Principio: quien produce información debe conocer esa información. Por ejemplo, una cooperativa cafetalera que provee servicios de crédito debe publicar la siguiente información: área de café de cada socio, quintales de café entregados, rendimiento de ese café en el beneficiado seco, precio al que se vendió, empresa que compró el café, valor total, costos de exportación y de administración, valor total pagado, monto de crédito dado a cada socio, tasa de interés, deuda, deuda pagada, monto de crédito recibido por la cooperativa de fuentes externas, tasas de interés y distribución por asociado. El solo

16 La Cooperativa José Alfredo Zeledón (JAZ), ubicada en San Juan del Río Coco, superó el sistema de habilitación a través de lograr una cartera de crédito sobre la base de los ahorros/aportaciones de sus asociados desde el mismo año de su fundación en 1995. Esa regla de aportar ya se volvió costumbre, ya no es resistida porque los asociados ven los beneficios: tienen crédito y además abarataron el costo de ese dinero. En consecuencia, esa organización ha diversificado sus amistades y ha cultivado mayor autonomía; sin embargo, aún trabaja en transitar de un modelo 'lider-seguidor' hacia una organización con liderazgos colectivos y compartidos, y de incidir para que sus asociados pasen de agricultura extensiva a una intensiva (Mendoza, 2012b).

17 La Cooperativa Solidaridad de la comunidad de Aranjuez logró aumentar el rendimiento productivo del café de sus asociados quebrando el mito de la bi-anualidad, articularse con su organización de segundo grado CECOCAFEN para que le de servicios de procesamiento de café, y negociar directamente con los compradores de su café de calidad. Es la única cooperativa que logró frenar a la roya. ¿Cómo lo ha hecho? Acordaron reglas para intensificar sus cafetales: usar premio del comercio justo para invertir en café, hacerlo bajo reglas acordadas, con supervisión directa del técnico, y entregando el premio no en efectivo sino en insumos -reglas que sus asociados cumplen a cabalidad. E igual que la cooperativa JAZ, han diversificado sus amistades y construido su autonomía; ellos van transitando hacia un liderazgo colectivo y compartido. Su limitante es que no tienen cultura de ahorro-aportaciones. (Mendoza 2013a) 
hecho de que cada asociado acceda abiertamente a esta información, sin restricción alguna, les permite preguntar, aprender, vincularse y gobernar su organización.

Una organización donde sus asociados cumplen las reglas acordadas (sea para aportaciones o para el manejo de las fincas cafetaleras), participan en las decisiones de su organización siguiendo el camino indicado en sus propios estatutos, deliberadamente buscan compartir sus lecciones y aprender de otras organizaciones, y son transparentes e informados de lo que su organización busca y camina, constituye una organización exitosa. Esta cooperativa no caerá en el despotismo, evitará el futuro de 'enano cabezón', resistirá ser absorbida por el mercado y no será cooptada por élites políticas. Este tipo de organización es un medio que contribuirá a expandir la capacidad humana milenaria del ser campesino-indígena. Pero, ¿lo lograrán solos? He ahí la importancia de alianzas estratégicas entre organizaciones con un enfoque de liderazgo que vamos proponiendo. La siguiente sección completa este punto.

\section{En las organizaciones que proveen servicios}

Aunque en esta sección nos centramos a las $\mathrm{ONG}$, con las debidas adaptaciones lo dicho aquí es aplicable a la situación de las instituciones financieras, organismos del comercio justo, centros de educación (universidades, institutos técnicos) y de investigación, e instituciones del Estado. Rocha (2011), citando al Directorio de ONG de Nicaragua 1999-2000, afirma que para el año 2000 había 322 ONG, 6\% de las cuales surgieron antes de 1980, 22\% en la década de 1980 y 72\% en la de 1990. Bodán (2000), basado en MINGOB (Ministerio de Gobernación), afirma que para el 2000 habían 1,861 ONG. Rocha también refiere que MINGOB afirmaba que había 4,360 asociaciones sin fines de lucro en Nicaragua. Ciertamente ha habido un boom de organizaciones en los últimos 30 años, específicamente las $\mathrm{ONG}$, tanto en Nicaragua como en América Latina. Rocha (2011) hace un balance sobre las ONG en Centroamérica:

Durante las décadas que siguieron a los conflictos armados las ONG han desarrollado innumerables y encomiables tareas. A la par, hay que cuestionar su cortoplacismo, su tendencia a la despolitización, su sumisa dependencia de los fondos del Norte. Y principalmente, su contribución al declive del trabajo asalariado y a la precarización del empleo. Algo muy grave en este reino del desempleo que es hoy Centroamérica.

¿Qué es lo que ha pasado con las ONG y las organizaciones en general? Petras y Veltmeyer (2005) afirman que las ONG sirvieron de agentes de los organismos internacionales para calmar a los pueblos y evitar posibles rebeliones en reacción a las políticas neoliberales. Hale (2002) hace notar que las políticas culturales del neoliberalismo son aún más graves que las políticas de asimilación de la era anterior, y que en esto los movimientos indígenas fueron burocratizados u oenegeizados a través de políticas y recursos que generan dicotomía entre el 'indio permitido', a quien promueven, y el 'indio rebelde', a quien excluyen y descalifican. Entonces, a diferencia del caso de las cooperativas, aquí nos encontramos con una situación 
adversa, no son las reglas informales que pasan encima de las reglas formales y afectan la autonomía de las organizaciones, sino más bien el sometimiento hacia reglas formales que responden al mercado lo que ha contribuido hacia el modelo de desarrollo de agricultura extensiva.

La Ilustración 6 revela el mito de la 'superioridad' de las ONG (nacionales e internacionales). Por un lado, ellas conocen las necesidades de la gente, tienen razón, deciden, dan luz, cambian la vida de la gente y sus fincas, hacen que las comunidades tengan historia; y por el otro lado, consideran que los productores 'no saben,' 'no cambian' y que son 'pobrecitos', lo que calza con la mentalidad de la gente expresada en las Ilustraciones 1 y 4 . Para las $\mathrm{ONG}$ las comunidades no son fuente de saber, por lo que voltean la mirada hacia la real fuente -donantes, mercado y academia, líderes, gurús, jefes, técnicos- para desde ahí 'atender,' 'asistir,' 'financiar,' 'empoderar,' 'sensibilizar' y 'concientizar.' Las ONG son campeonas en fomentar procesos de 'abajo hacia arriba' a través de métodos participativos, mientras en la práctica tienen definidas sus reglas (políticas) para ejecutar sus recursos ${ }^{18}$. La naturalización de estas prácticas es tan profunda que las organizaciones enarbolan el mito del empoderamiento: el líder empodera a su seguidor, proceso en el que se asume que quien empodera tiene poder, y quien es empoderado carece de poder.

Este empoderamiento que des-empodera es complementado por el mito del gran 'gurú', el líder salvador y gran visionario. Se cree que solo un líder hace a una

18 En el caso de las microfinancieras debemos notar que muchas de ellas comenzaron como fondos rotativos y revolventes, organizando grupos de fianza solidaria -bastante descentralizados, organizando círculos de ahorro y crédito. Al inicio también enfatizaron el estudiar a las comunidades y sus familias. Con el tiempo se fueron profesionalizando, sus políticas se estandarizaron, cada vez más fueron absorbidas por la legislación formal, se centraron en individuos en lugar de circulos, dejaron de estudiar a las comunidades y sus familias, respondieron cada vez más a los mercados, viraron hacia tener escala y ganancias, y se fueron más hacia una cartera comercial y (peri) urbana. Las comunidades dejaron de ser fuente de saber para las microfinancieras. A mayor institucionalización más distancia de las comunidades y por lo tanto la brecha entre las gerencias centrales y las gerencias de las sucursales y con los promotores de crédito es mayor -quienes conocen más a las comunidades cada vez deben esconder su saber para responder a las politicas de su organización. 
organización $^{19}$. Su impacto en una organización hace que los seguidores se sientan líderes frente a las comunidades y por eso 'asisten'... y frente a la estructura de su organización se sienten seguidores, la ONG se ve seguidora frente a los donantes... y se siente líder frente a las comunidades para 'asistirlos'... La idea de líder viene de tener seguidores. Es una relación asimétrica donde ambos quedan como 'gallina maneada': el líder, sesgado por la relación líder-seguidor, ve a su segundo (al que le sigue en cargo) generalmente como su competidor, o la rectoría de una universidad, o a las/os directores de facultades e institutos. Así se profundiza una antigua regla social de supervivencia en las estructuras de poder: los segundos están para apoyar, jamás para destacarse o serán ninguneados o despedidos; o los segundos justamente por su mentalidad que subyace la relación líder-seguidor se comportarán como 'seguidor' sea para someterse o para rebelarse ubicándose como 'seguidor' de otro jefe mayor. Esto es estar 'maneados': sin mucho movimiento para saltar, algo que muchas veces es justificado como "poco pero bien", pero que perjudica a ambos y a la efectividad de la organización en su conjunto.

La trampa está en la relación social líder-seguidor de la ONG en matrimonio con la relación social patrón-cliente de la población. Ese casamiento, cimentado en siglos, se halla cómodo con el contexto de 'cultura extensiva' que ha producido despojo, desigualdad y pobreza, lo que explica por qué proyectos pro sostenibilidad ambiental, equidad de género, crédito y asistencia técnica en favor de la productividad, no hayan resultado. Es cómodo por haberse ubicado en áreas relativamente aisladas, cómodo para un tipo de comercio extractivo basado en el sistema de habilitación de un capitalismo que combina mercado con habilitación en línea, con relaciones de patronazgo. Como dijimos antes, ese matrimonio no solo está cómodo, sino que impide aprovechar el contexto de cambio en el que se encuentra el mundo agropecuario.

¿Cómo las y los intelectuales de las organizaciones pueden superar su alma de seguidor y ser líderes, y con ello contribuir a la transformación de la relación patrón-cliente en las comunidades? Igual que con las cooperativas, despertar a través de des-aprender es el punto de partida. De hecho, el que las organizaciones se reconozcan en la Ilustración 6 es un punto de partida, ese despertar implica que deben 're-voltear' la mirada hacia las comunidades con quienes negociar -entenderse, discernir y producir- conocimiento. Este paso, sin embargo, es insuficiente. Muchas organizaciones se complacen en hacerse auto-críticas manteniéndose en la estructura líder-seguidor. Son como las movilizaciones populares que gritan consignas oponiéndose a alguna política pero que carecen de pensamiento alternativo o que llegan al gobierno y no pasa nada (ver en la Ilustración 4: "Nuestro líder ya es Ministro, estamos en el poder."). Les pasa lo que les sucede a los perros de una comunidad rural que salen ladrando con todas su fuerzas detrás del carro que pasa, y cuando al fin alcanzan al carro no pasa nada, regresan con el rabo entre las piernas y al encontrarse con otro perro le reclaman por ser 'cabeza agachada' (no sumarse a la ladrada). El despertar -o sea, percibir las limitaciones de esa relación, darse cuenta de esa asimetría que nos deja 'maneados'- es un buen paso, pero sin superar el

19 Collins y Porras (1994, pp. 31-34) encuentran que no hay correlación entre grandes y carismáticos visionarios lideres, y las compañias visionarias. 
esquema líder-seguidor el amor por esa relación re-aparecerá.

¿Qué mecanismos ayudarían a superar esa estructura y hacer que ese punto de partida de 'despertar' 're-volteando' la mirada hacia las comunidades, sea sostenido? La Ilustración 7 resume dichos mecanismos. Primero, en vez de $\checkmark \quad$ Control: decisiones compartidas a partir
de procesos de emancipación
$\checkmark \quad$ Competencia: inserción, inmersión,
escritura y diálogo
$\checkmark \quad$ Claridad: hacer alianzas co-produciendo
saber
Ilustración 7. Mecanismos de transformación empoderar, emanciparse: liberar energías, iniciativas, imaginación y creatividad de cada persona en un marco de grupos y reflexiones colectivas. Los actores de las organizaciones, comunidades y cadenas de valor precisan discernir sus realidades y de ese modo reconocerse como líderes viendo más allá de esas realidades. Evidenciar los mitos les despierta, des-aprenden, se libran de sus 'demonios' (mitos, creencias) y hay destellos de cambio. Pero esos 'demonios' suelen regresar, ¿cómo despedirse de ellos y llenar el vacío con saberes transformadores?

Contrario al empuje de la relación social líder-seguidor de separar los cuatro elementos de la Ilustración 8, haciendo que la inmersión sea solo para los estudiantes del norte, la inserción solo para los directores-rectoresgerentes, la escritura solo para los académicos de Europa y de los Estados Unidos, y el diálogo solo para los técnicos en terrenos 'guiados' por el mercado (capitalismo con tecnología mecanizada e intensiva) y siguiendo prácticas 'guiados' por el mito del empoderamiento, aquí, en el marco de liderazgos colectivos y compartidos, proponemos emanciparnos de esas ataduras. ¿Cómo?

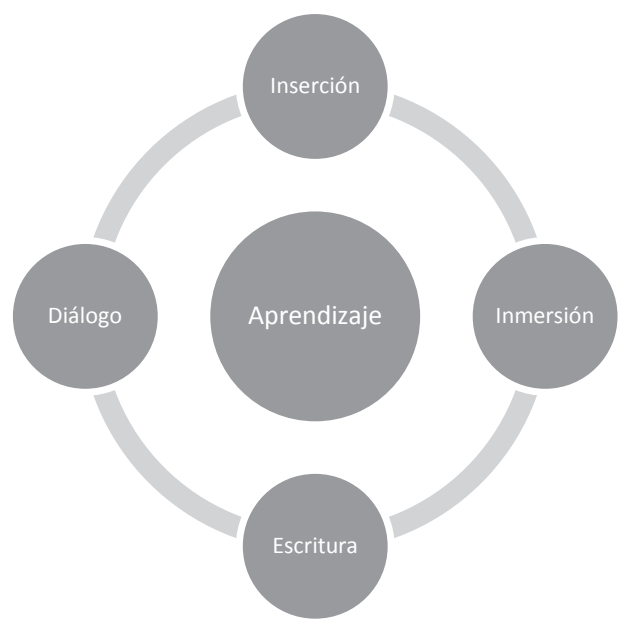

Ilustración 8. Camino de interacción de cuatro elementos para generar competencias

La Ilustración 3 nos muestra

el camino de interacción de cuatro elementos en torno al aprendizaje $\mathrm{e}^{20}$ que cada intelectual debe desarrollar en un marco colectivo y compartido -en lugar de responder solo a un tipo de mercado controlado por las transnacionales. Buscamos voltear

20 Esta Figura con los cuatro elementos viene de Mendoza (2013b). Lo descrito aqui se ha impulsado en el instituto Nitlapán-UCA. En este texto lo recupero como mecanismo fundamental desde el ángulo de 'liderazgos colectivos y compartidos.' La experiencia en Nitlapán muestra que se entiende su importancia y lo apropiado de la propuesta. Pero la institucionalidad referida de responder a los mercados (proyectos, rentabilidad financiera sin lo ambiental y lo social) es durísima de ser cambiada. Una lección que se presenta es que el cambio debe trabajarse de forma paralela y simultánea con las instituciones como Nitlapan, con las comunidades-territorios donde se trabaja, y con los organismos internacionales aliados. Otra lección es que el cambio hacia liderazgos colectivos y compartidos requiere de mayor rotación y renovación de liderazgos en cualquier institución, la ley de talón es que no hay personas imprescindibles. 
'la mirada invertida' hacia las comunidades-sociedades y sus mercados. El primer elemento es la inserción, tener perspectiva de largo plazo (crítica del y alternativa al contexto, narrativa y contra-narrativa) con sentido de misión (lucha política), a través de construir alianzas con las familias, sus comunidades y organizaciones. El segundo es la inmersión, que es quitarnos los zapatos y ponernos en los zapatos de las familias empobrecidas y empobrecedoras para entender la realidad desde sus mundos, literalmente dejarse "llevar" por la realidad del "otro/a". Esta inmersión da contenido a la inserción y la concretiza; si la inserción es teoría, la inmersión es método. El tercer elemento es escribir, tomar notas de cada conversación, observación y lecturas que emanan de la inserción e inmersión, y conceptualizarlas en tanto ideas y significados. Y el último elemento es el diálogo, que es flujo libre de ideas en grupos, que parte de reconocer la existencia de la otra persona, y que se mueve alrededor de la palabra. De aquí, inserción sin inmersión es vacía, inmersión sin inserción es ciega, las dos sin escritura se vuelven 'plática de presos', y los tres sin diálogo grupal carecen de transformación social colectiva. Esto es metanoia: aprendizaje que emancipa y transforma, y que construye organización visionaria.

Finalmente, cada persona que trabaja en las organizaciones necesita producir y compartir conocimiento a través de la interacción humana. Interactuar en grupos para buscarle solución a problemas específicos y para aprovechar oportunidades concretas. Las auditorías y misiones de evaluación son oportunidades privilegiadas para que el personal pueda contar sus problemas y sus dudas para beneficiarse de consejos e ideas de cómo otras organizaciones han enfrentado similares problemas. Se debe organizar sesiones de reflexión con investigadores visitantes y locales, invitando a personas de otras organizaciones; así como escribir artículos de una o dos páginas sobre múltiples y diversos temas, y publicarlos. El mayor desafío es leer y no la carencia de bibliografía, es escribir y no la falta de información, y es atreverse a reconocer las propias habilidades. Estos son los mecanismos que van en coherencia con la emancipación, que resulta de equipos que deciden, de hacer funcionar sus talentos, de expandir sus capacidades humanas.

\section{Conclusiones}

La relación social 'patrón-cliente' se ha casado con la de 'líder-seguidor' expresada en las formas de organización formal e informal, las que a su vez han respondido a un contexto de país que en el área rural ha sido caracterizado por la 'cultura extensiva y extractiva', que se ha traducido como ampliación de la frontera agrícola, expulsión sistemática de las familias más pobres, degradación ambiental y despojo. Sin embargo, ese contexto está cambiando, ya la frontera agrícola llegó al mar. Es raro encontrarnos familias en el centro-interior del país rotando entre sus áreas agropecuarias y área guatal. El cambio climático se hace sentir con más enfermedades para los rubros. Los suelos requieren ser alimentados. La multiplicación de la población y su creciente escolaridad es una realidad. Y la diferenciación de productos (p.ej. café orgánico, cafés especiales, derivados de la leche, hortalizas) a través de reorganizadas cadenas de valor, es cada vez más fuerte. Explicitar y generar conocimiento es un desafío para todos los sectores sociales, desde las familias campesinas hasta los técnicos e 
investigadores. Un productor estudioso de su finca, observador y analítico, técnicos que investigan para sustentar sus consejos técnicos, investigadores que hacen inmersión... son el futuro del país.

Este contexto de cambio, de un capitalismo voraz combinado con el sistema de habilitación y la cobija partidaria de 'compañero', nos revela que lo más valioso hoy en día es el trabajo cognitivo y no el trabajo físico humano, como ha sido el contexto de 'cultura extensiva y extractiva' con su consecuente matrimonio entre patrón-cliente y líder-seguidor. Las organizaciones (cooperativas, ONG, centros de investigación, microfinancieras) han creado su propia muralla respondiendo a su esquema 'líder-seguidor' con la mirada en dirección opuesta a las comunidades buscan ser más estandarizadas, profesionalizadas y grandes. Aun con las diferencias entre cooperativas y comunidades y cadenas de valor, donde el peso de las reglas informales moldean comportamientos y resultados, y en el caso de las organizaciones (ONG, microfinancieras...) que más bien se observan prisioneras de las reglas formales, ambas son movidas por las fuerzas del mercado. El nuevo contexto de cambio, sin embargo, corre el riesgo no tanto de no ser aprovechado debido al imperio del matrimonio del enfoque patrón-cliente y líder-seguidor, y por el enfoque neoliberal, sino de ser aprovechado por una élite transnacional capaz de maniobrar ambos enfoques generando aún más desigualdad y despojo en el país.

En este artículo hemos propuesto un enfoque de 'liderazgos colectivos y compartidos' que rompa con la relación social del 'matrimonio' y la ideología neoliberal. Para ello hemos anotado mecanismos que permitan a las organizaciones (cooperativas, ONG, microfinancieras, centros de investigación) 're-voltear' su mirada, preguntarse por su génesis, y hacer de sus organizaciones escuelas de aprendizaje visionarias casadas con actores de las comunidades y de las cadenas de valor expresando rutas que van 'más allá del desarrollo'. Esto es posible si las organizaciones estudian a las comunidades y se auto-estudian a sí mismas a fin de encontrar lo que Brafman y Beckstrom (2007) llaman 'el punto del caramelo': encontrar el punto apropiado entre centralización y descentralización de acuerdo a sus procesos específicos. En el largo plazo, la organización es lo que importa, aquella que supere la relación 'líder-seguidor' y lo haga en alianza con las comunidades que vayan superando la relación 'patrón-cliente', encontrando 'el punto del caramelo', serán las organizaciones que persistan y las que contribuyan realmente a la transformación societal.

¿Persistirá su organización en el largo plazo contribuyendo a la transformación societal? La respuesta la tiene cada miembro. Si responde desde un marco líderseguidor, aun siendo líder es un seguidor, por lo que ya perdimos la carrera aun antes de arrancar. Si responde desde un marco líder-líder hay perspectiva porque ya ganamos un líder -sea mujer u hombre. 


\section{Referencias bibliográficas}

Bastiaensen, J., Marchetti, P., Mendoza, R. \& Pérez, F. (2013). Las paradójicas secuelas del 'Movimiento No Pago' en las microfinanzas agropecuarias en Nicaragua. Encuentro (95), 47-68.

Baumeister, E. (2010). El caso de Nicaragua. En Proyecto Dinámica de la Tierra en América Latina y el Caribe. Mimeo.

Baumeister, E. \& Fernández, E. (2007). Sobre las migraciones regionales de los nicaragüenses. Managua: INCIDES.

Bodán, O. (2000). ONGs-gobierno: matrimonio por conveniencia. Confidencial (233). Recuperado el 20 de junio de 2014, de http://www.confidencial.com. ni/archivo/2000-233/actualidad.html

Brafman, O. \& Beckstrom, R. (2007). La araña Ë la estrella de mar: La fuerza imparable de las organizaciones sin mandos. Argentina: Empresa Activa.

Boudon, R. (1981). The Logic of Social Action: An Introduction to Sociological Analysis. London: Routledge \& Kegan Paul.

CIPRES. (2008). Las Cooperativas Agroindustriales en Nicaragua. Análisis socioeconómico de 10 organizaciones que integran a 171 cooperativas. Managua: CIPRES, UNAG, CCS.

Collins, J. \& Porras, J.I. (1994). Built to Last: Successful Habits of Visionary Companies. New York: Harper Business.

Covey, S. (2012). Foreword. In: L. D. Marquet. Turn The Ship Around! How to Create Leadership at Every Level. (pp. xi - xiv). Austin: Greenleaf Book Group Press.

Farrant, A., Mcpahil, E. \& Berger, S. (2012). Preventing the "Abuses" of Democracy: Hayek, the "Military Usurper" and Transitional Dictatorship in Chile? American Journal of Economics and Sociology, 71, (3). Recuperado en julio de 2012, de http://coreyrobin.files.wordpress.com/2012/07/hayekchile.pdf

Fernández, E. (2013). El patriarcado. Managua: FVP. Mimeo.

Hale, C. (2002). Does Multiculturalism Menace? Governance, Cultural Rights and the Politics of Identity in Guatemala. Journal of Latin American Studies, 34 (3), 485-524.

Hayek, F. A. (1944). The Road to Serfdom. London: Routledge Press.

Hayek, F. A. (1988). The Fatal Conceit: The Errors of Socialism. Chicago: The University of Chicago Press.

Jiles, J. (2005). Internet Encyclopaedias Go Head to Head. Nature (438), 900-901. Recuperado en enero de 2014, de http://www.u.arizona.edu/ trevors/ nature_15dec2005_wikipedia.pdf

Marquet, L. D. (2012). Turn The Ship Around! How to Create Leadership at Every Level. Austin: Greenleaf Book Group Press.

Martínez, S. (2013). Analysis of dynamics of power relations in the chain of beans in Nicaragua: Impact of the policy export regulation. [Case study from Río Blanco]. Tesis de maestría. Amberes: IOB-Universidad de Amberes.

Mendoza, R. (1990). Costos del verticalismo: Un FSLN sin rostro campesino. Envío, (107). Recuperado el 10 de enero de 2014, de http://www.envio.org.ni/ articulo/640 
Mendoza, R. (2012a). Gatekeeping and the struggle over development in the Nicaraguan Segovias. Disertación doctoral. Amberes, Bélgica: University of Antwerp-IOB.

Mendoza, R. (2012b). Nicaragua - 33 Aniversario de la Revolución: Café con aroma de cooperativas. Envio, (364). Recuperado el 10 de enero de 2014, de http:// www.envio.org.ni/articulo/4548

Mendoza, R. (2013a). Nicaragua: El café en los tiempos de la roya. Envío, (372). Recuperado el 12 de enero de 2014, de http://www.envio.org.ni/articulo/4653

Mendoza, R. (2013b). Inmersión, inserción, escritura y diálogo: Una ruta para el aprendizaje. Managua: Nitlapán. Mimeo.

Mendoza, R., Gutiérrez, M. E., Preza, M. \& Fernández, E. (2012). Las cooperativas de café de Nicaragua: ¿Disputando el capital del café a las grandes empresas? Observatorio Social, Cuadernillo (13). Recuperado el 5 de enero de 2013, de http://observatoriosocial.com.ar/dev/pub_cuadernos.html

Myers, N. (1981). The Hamburger Connection: How Central America's Forests Become North America's Hamburgers. AMBIO, 10 (1), 3-8.

Nevins, T. (2004). Introduction. En: H. Ingstad. The Apache Indians: In Search of the Missing Tribe. Lincoln: University of Nebraska Press.

Pérez Baltodano, A. (2003). Entre el Estado Conquistador y el Estado Nación: Providencialismo, pensamiento político y estructuras de poder en el desarrollo histórico de Nicaragua. Managua: IHNCA-UCA.

Petras, P. \& Veltmeyer, H. (2005). Movimientos sociales y poder estatal: Argentina, Brasil, Bolivia y Ecuador. México, D.F.: Lumen.

Rocha, J. L. (2011). Los Jinetes del desarrollo en tiempos neoliberales (3): Segundo jinete: las ONG. Envío, (354). Recuperado el 10 de enero de 2012, de http:// www.envio.org.ni/articulo/4400

Romero, M. \& Collado, C. (2013). Acercamiento a las estrategias de vida de las familias rurales de Matiguás y Río Blanco. Cuaderno de Investigación (47). Managua: Nitlapan-UCA.

Romero, M., Collado, C. \& Bastiaensen, J. (2013). El cacao y el frijol ¿Oportunidades de inclusión para las familias rurales? Cuaderno de Investigación (49). Managua: Nitlapan-UCA.

Stack, J. (1992). The great Game of Business. New York: Crown Business. 